\title{
PECUÁRIA FAMILIAR NO MUNICÍPIO DE CAÇAPAVA DO SUL/RS: ASPECTOS HISTÓRICOS, SOCIAIS E PRODUTIVOS
}

\author{
T. R. de FREITAS ${ }^{1}$, C. L. AGNE ${ }^{2}$, A. MATTE ${ }^{3}$ \\ Universidade Estadual do Rio Grande do Sul ${ }^{1,2}$, Universidade Tecnológica Federal do Paraná ${ }^{3}$ \\ ORCID ID: https://orcid.org/0000-0002-1283-8746 ${ }^{1}$ \\ tyagodefreitas@gmail.com ${ }^{1}$
}

Submetido em 08/04/2020 e aceito em 16/10/2020

DOI: $10.15628 /$ holos.2020.9865

\section{RESUMO}

O objetivo desse estudo é analisar os aspectos históricos, sociais e produtivos da pecuária familiar no município de Caçapava do Sul, no sul do Rio Grande do Sul - RS. A pesquisa foi caracterizada como qualitativa, sendo que os dados foram coletados por meio de entrevistas históricas aplicadas a 16 pecuaristas familiares, entidades de representação, órgãos públicos e historiadores locais do município. Os resultados indicaram dois tipos de pecuaristas familiares: tradicional e de transição. $O$ primeiro foi originado a partir do processo histórico de ocupação do território e divisão de terras ocorrido na época das sesmarias. O segundo apresenta semelhanças com a agricultura familiar, caracterizado pela migração da atividade agrícola para a pecuária. Apesar das diferenças de formação e de comportamento para a obtenção da renda, os dois tipos se assemelham quanto à incerteza da continuidade da atividade. Estudos que busquem entender perfis e trajetória histórica da pecuária familiar são necessários para elaborar políticas públicas condizentes à sua diversidade.

PALAVRAS-CHAVE: Agropecuária. Bioma Pampa. Pecuaristas Familiares. Tradição.

\section{LIFESTOCK FAMILY FARM IN CAÇAPAVA DO SUL, RIO GRANDE DO SUL- BRAZIL: HISTORICAL, SOCIAL AND PRODUCTIVE ASPECTS}

\section{ABSTRACT}

The aim of this study is to analyze the historical, social and productive aspects of family farming in the municipality of Caçapava do Sul, in the south of Rio Grande do Sul - RS. The research was characterized as qualitative, and the data were collected through historical interviews applied to 16 family ranchers, representative entities, public bodies and local historians in the municipality. The results indicated two types of family farmers: traditional and transitional. The first was originated from the historical process of occupation of the territory and division of land that occurred at the period of the sesmarias. The second shows similarities with family farming,
\end{abstract}

characterized by the migration from agricultural activity to livestock. Despite the differences in origin and behavior for obtaining income, the two types are similar in terms of the uncertainty of the continuity of the activity. Studies that seek to understand profiles and historical trajectory of family farming are necessary to develop public policies in line with their diversity.

KEYWORDS: Agriculture. Pampa Biome. Livestock family farm. Tradition. 


\section{INTRODUÇÃO}

O processo de ocupação demográfica da porção sul do Rio Grande do Sul teve significativa influência sobre a constituição histórica da região. Por um longo período de tempo, foi formada principalmente por propriedades rurais com extensas áreas de terra e pela baixa representatividade de pequenos estabelecimentos. Especialmente no sul do estado, a criação pecuária figurava como a principal atividade produtiva durante o século XVII, sobretudo pela criação de bovinos e de ovinos, favorecida pela oferta e predominância de pastagem nativa típica

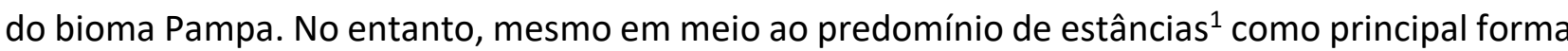
de ocupação, esse processo não eliminou a emergência e a reprodução de formas familiares de produção pecuária. Inicialmente, esses produtores familiares desenvolviam a criação pecuária à sombra das estâncias e em áreas marginalizadas que não despertavam o interesse dos estancieiros (MATTE; SPANEVELLO; ANDREATTA, 2015; RIBEIRO, 2016).

No decorrer das últimas décadas, por meio do processo mobilizado especialmente por organizações que atuam diretamente com pecuaristas no Pampa, aliado às pesquisas acadêmicas, é legitimada a denominação de Pecuarista Familiar como mecanismo de reconhecimento de uma forma familiar de produção realizada nesse contexto (ANDREATTA, 2016; MATTE; WAQUIL, 2018; MATTE et al., 2020). Assim, a pecuária familiar passa a ser reconhecida pelo Estado do Rio Grande do Sul, caracterizada como atividade que realiza a cria ou a recria de bovino com finalidade de corte, podendo desenvolver também a criação de ovinos, caprinos e bubalinos (RIO GRANDE DO SUL, 2016; RIBEIRO, 2016). Conforme estudos encontrados na obra organizada por Waquil et al. (2016), deve-se conceber o pecuarista familiar como um ator social diferenciado étnica e culturalmente, ligado a um conjunto de fenômenos históricos, conferindo-lhes diversidade, representado pelos modos de vida e pelas estratégias de produção e reprodução adotados, que acabam por conduzir à diferenciação nas dinâmicas de desenvolvimento.

No caso do município de Caçapava do Sul, localizado na região da Campanha gaúcha, a pecuária é uma das atividades predominante. A criação extensiva de bovinos de corte e ovinos foi a principal atividade por um longo tempo, permanecendo como uma das principais fontes de sustentação econômica do município. Conforme dados do Censo Agropecuário 2017 (IBGE, 2019), 93\% (2.468) dos estabelecimentos rurais do município desenvolvem a atividade pecuária e criação de outros animais. Observa-se que os estabelecimentos rurais com até 200 hectares somam 85,6\%, representando em número absoluto 1.759 unidades. Porém, estima-se que há um número maior de pecuaristas familiares, já que a delimitação legal é de 300 hectares.

Os estudos sobre a pecuária familiar na região carecem de análises que possam identificar mudanças e trajetórias históricas. Tais dados poderão auxiliar na compreensão sobre a diversidade da atividade e dos produtores envolvidos, servindo como subsídios para a elaboração de ações e

\footnotetext{
${ }^{1}$ Segundo Cesar (2005) o substantivo pertence ao latim stare (estar em pé, estar firme) e stantia (coisas que estão de pé, paradas), desta forma estância é o lugar onde se fica, se estabelece morada. Assim, portanto "estaciar" significa estabelecer.
} 
políticas públicas. Dessa forma, este artigo teve como objetivo compreender as características da pecuária familiar desenvolvida no município de Caçapava do Sul, buscando identificar a trajetória e perfis de pecuaristas familiares.

O texto está subdividido em cinco partes, contando esta introdução e as considerações finais. Na segunda seção do texto são apresentadas as principais definições e abordagens envolvendo a categoria de pecuaristas familiares e uma breve trajetória histórica do município de Caçapava do Sul. Na terceira seção são descritas as etapas e técnicas utilizadas na pesquisa. Os resultados serão apresentados na quarta seção. $O$ artigo encerra com as considerações finais.

\section{PECUÁRIA FAMILIAR E A TRAJETÓRIA HISTÓRICA DE CAÇAPAVA DO SUL}

Nesta seção serão apresentadas algumas definições sobre a pecuária familiar e a identificação de elementos que norteiam a emergência desta categoria social, finalizando com uma breve caracterização do município de Caçapava do Sul.

\subsection{Definindo pecuária familiar}

A compreensão da definição da pecuária familiar pode ser estabelecida a partir de dois pontos. O primeiro refere-se à Lei no 13.515, que regulamenta o Programa Estadual de Desenvolvimento da Pecuária de Corte Familiar - PECFAM, instituído em 13 de setembro de 2010. Tal programa estabelece critérios para fins de identificação e enquadramento dessa categoria social. O segundo diz respeito às contribuições da literatura acadêmica, levando em consideração as variações presentes em diversos contextos empíricos. Esses estudos estão atrelados aos grupos de pesquisas de universidades, sobretudo para repensar elementos que tem sustentado a Lei da pecuária familiar no Estado do Rio Grande do Sul (WAQUIL et al., 2016).

Sobre as definições legais, o enquadramento do pecuarista familiar é apresentado no decreto $\mathrm{n}$ 0 48.316, de 31 de agosto de 2011, que regulamenta o PECFAM e apresenta as seguintes definições:

Art. 3 ㅇ São considerados pecuaristas familiares os produtores que atendam simultaneamente às seguintes condições: I - Tenham como atividade predominante a cria ou a recria de bovinos e/ou caprinos e/ou bubalinos e/ou ovinos com a finalidade de corte; II - Utilizem na produção trabalho predominantemente familiar, podendo utilizar mão de obra contratada em até cento e vinte dias ao ano; III - Detenham a posse, a qualquer título, de estabelecimento rural com área total, contínua ou não, inferior a trezentos hectares; IV - Tenham residência no próprio estabelecimento ou em local próximo a ele; $V$ - Obtenham no mínimo setenta por cento da sua renda provinda da atividade pecuária e não agropecuária do estabelecimento, excluídos os benefícios sociais e os proventos previdenciários decorrentes de atividades rurais.

O decreto que regulamenta a pecuária de corte no estado do Rio Grande do Sul apresentou avanços no enquadramento desta categoria social. Tais avanços ocorreram após as publicações de 
vários estudos que contribuíram na descrição do perfil desta atividade, principalmente na maneira que o pecuarista conduz os seus sistemas de criação perante o tamanho da propriedade (ANDREATTA, WAQUIL, MIGUEL, 2016).

De tal modo, Waquil et al. (2016) esclarecem que a pecuária familiar passou a ser descrita por instituições de ensino, pesquisa e extensão rural em 2000, apresentando diferentes abordagens que incluem aspectos como o trabalho familiar e as relações com o meio produtivo. Dessa forma, os autores descrevem essa categoria social como um grupo familiar que tem a execução das atividades sustentadas na mão de obra da família, sendo caracterizada pela coprodução com a estreita relação com a natureza, onde os recursos econômicos provem, principalmente, da criação de bovinos e ovinos de corte. Sobre a relação com a natureza, a pecuária desenvolvida sobre o bioma Pampa diferencia-se do cenário nacional, ao passo que a principal fonte de alimentação dos animais permanece sendo o campo nativo, que compreende uma vasta extensão de pastagens naturais, típicas desse bioma (CARVALHO et al., 2006; BORBA, 2016; NABINGER, 2006).

As particularidades existentes em cada propriedade rural estão relacionadas com a forma de interação da família com a história, meio social e cultura, elementos que condicionam a identidade local. Além disso, tais aspectos contribuem para que haja uma variação de diferentes perfis socioeconômicos, refletindo na maneira como os pecuaristas familiares conduzem as suas atividades em suas propriedades rurais.

A diversidade relacionada aos pecuaristas foi apontada em pesquisas anteriores, como é o caso da autora Andreatta (2009), que desenvolveu um estudo sobre a bovinocultura de corte gaúcha, sendo este realizado em 117 municípios do RS. Tal estudo permitiu descrever o perfil social e econômico destes pecuaristas, o qual foi caracterizado em quatro tipos: o pecuarista estacionário, o pecuarista consolidado, o pecuarista lavoureiro especializado e o pecuarista lavoureiro convencional. Já o estudo de caso realizado por Cotrim (2003) com pecuaristas familiares no município de Canguçu - RS, constatou três tipos de pecuaristas familiares, sendo eles o pecuarista familiar tradicional, o pecuarista familiar pluriativo e o pecuarista familiar comercial.

Considerando os quatro tipos de pecuaristas descritos por Andreatta (2009), o pecuarista denominado como "estacionário" é a categoria em que o chefe do estabelecimento apresenta a maior média de idade, com menor nível de escolarização, sendo que a atividade predominante é a bovinocultura de corte. Além da bovinocultura como principal atividade, o pecuarista denominado "consolidado" apresenta baixos indicadores econômicos, mas o suficiente para garantir a reprodução social, tendo também a entrada de outros recursos, oriundos de outras fontes de renda. O pecuarista identificado como "lavoureiro especializado" tem um caráter empresarial, com faixa média de idade mais baixa quando comparada aos demais tipos e com um maior nível de escolaridade. E por fim, o pecuarista "lavoureiro convencional" é descrito com similaridade ao tipo anterior, mas tendo suas principais particularidades em relação à mão de obra (que é contratada), e renda superior aos demais tipos.

Corroborando com a autora, o estudo recente realizado por Moreira, Conterato e Matte (2019), sobre pecuaristas de corte no sul do Rio Grande do Sul, ao analisar a relação desses 
produtores com o avanço da soja, constataram o predomínio de dois tipos de pecuaristas predominantes, quais sejam: os Pecuaristas Tradicionais e os Pecuaristas Sojicultores. Esse segundo tipo emerge diante do incentivo quanto à produção de lavouras, o que tem sido alvo de incertezas quando à continuidade do Pampa e da atividade pecuária (MATTE, 2019; MATTE; WAQUIL, 2020).

No estudo de Cotrim (2003) há o delineamento de três perfis de pecuaristas familiares para o município de Canguçu, no sul do estado, são eles: o tradicional, o pluriativo e o comercial. 0 autor aponta que o pecuarista familiar tradicional é aquele que teve a sua origem a partir dos primeiros povoadores do município, ocupando áreas a partir da distribuição de sesmarias. 0 pecuarista familiar pluriativo é aquele que atuava como trabalhador de estâncias de criação pecuária. Por fim, o pecuarista familiar comercial está localizado em maiores áreas de terra que os demais tipos, tendo descendência de italianos, adquirindo a terra por meio de compra, fato que o distingue dos demais já que obtiveram a propriedade por meio de herança.

Somado a isso, a criação de gado, além de estar diretamente relacionada à cultura de identificação destes homens ao campo, também é uma garantia da segurança para subsistência da família como mercadoria de reserva, comercializando de acordo com as necessidades (RIBEIRO, 2003; MATTE et al., 2020). Segundo Matte, Spanevello e Andreatta (2015), em estudo no município de Dom Pedrito, localizado no sul do RS, as interpretações e manifestações associadas a um tipo de exploração está consorciada a farta disponibilidade de recursos naturais do bioma Pampa.

De modo geral, Matte, Spanevello e Andreatta $(2015 ; 2016)$ e Ribeiro $(2009 ; 2016)$ afirmam que a pecuária de corte realizada por estas famílias apresenta características que os diferencia dos agricultores familiares, sendo elas: a) a principal atividade exercida na propriedade é a criação pecuária sobre pastagem nativa com baixa utilização de insumos externos, onde os animais constituem como mercadoria reserva; b) apresenta um certo grau de autonomia em relação aos mercados possibilitando a venda de acordo com a necessidade; c) uso da mão de obra familiar de forma predominante e com relação de troca de serviços com vizinhos; d) presença e a importância significativa da aposentadoria rural; e) o consumo familiar representado pelas carnes, principalmente bovina e ovina.

O pecuarista familiar tem a partir da sua identidade cultural com o meio em que vive um importante papel, tendo em uma atividade extensiva de criação pecuária de baixo retorno financeiro em curto prazo, sendo esta forma de garantir a sua reprodução social. Tais características condicionam a identidade de muitos pecuaristas, muito embora sejam negligenciadas em detrimento da supervalorização da função econômica (COTRIM, 2003). Dessa forma, os pecuaristas familiares dedicados ao desenvolvimento da atividade de bovinocultura de corte não estão ligados especificadamente à busca intensiva do lucro econômico. A principal justificativa é a relação mais intensa com as questões familiares, desenvolvendo uma atividade de escolha de caráter pessoal, tornando uma alternativa de estilo de vida (MATTE, 2019; MATTE et al., 2020).

No que diz respeito à história do município de Caçapava do Sul, a pecuária familiar permanece como importante protagonismo e predomínio entre as formas de produção presentes 
no meio rural. O processo que transcorreu de extensas áreas de terra na ocupação do território, para subdivisões e mudanças socioeconômicas levou ao predomínio dessa categoria e permitiu o seu reconhecimento pelo Estado. Partindo do exposto, o próximo tópico descreve os elementos que permitem apresentar as características do município em que a pecuária familiar foi analisada.

\subsection{Uma breve caracterização do município de Caçapava do Sul}

O município de Caçapava do Sul foi fundado em 25 de outubro de 1831 e encontra-se na região da serra do Sudeste, parte sul do Rio Grande do Sul. Possui uma área de $3.047,1 \mathrm{~km}^{2}$ e está localizado a uma distância de $259 \mathrm{~km}$ da capital do estado, Porto Alegre (IBGE, 2015). Segundo os dados do Censo demográfico, a população do município tem um total de 33.690 habitantes, sendo que 25.420 (75\%) residem na zona urbana e 8.280 habitantes (25\%) na área rural (IBGE, 2010). Quanto ao aspecto geográfico, está delimitado pelos municípios: São Sepé, Cachoeira do Sul, Santana da Boa Vista, Pinheiro Machado, Bagé e Lavras do Sul, conforme a Figura 01.

Figura 1: Divisão do estado do Rio Grande do Sul por município com destaque para Caçapava do Sul

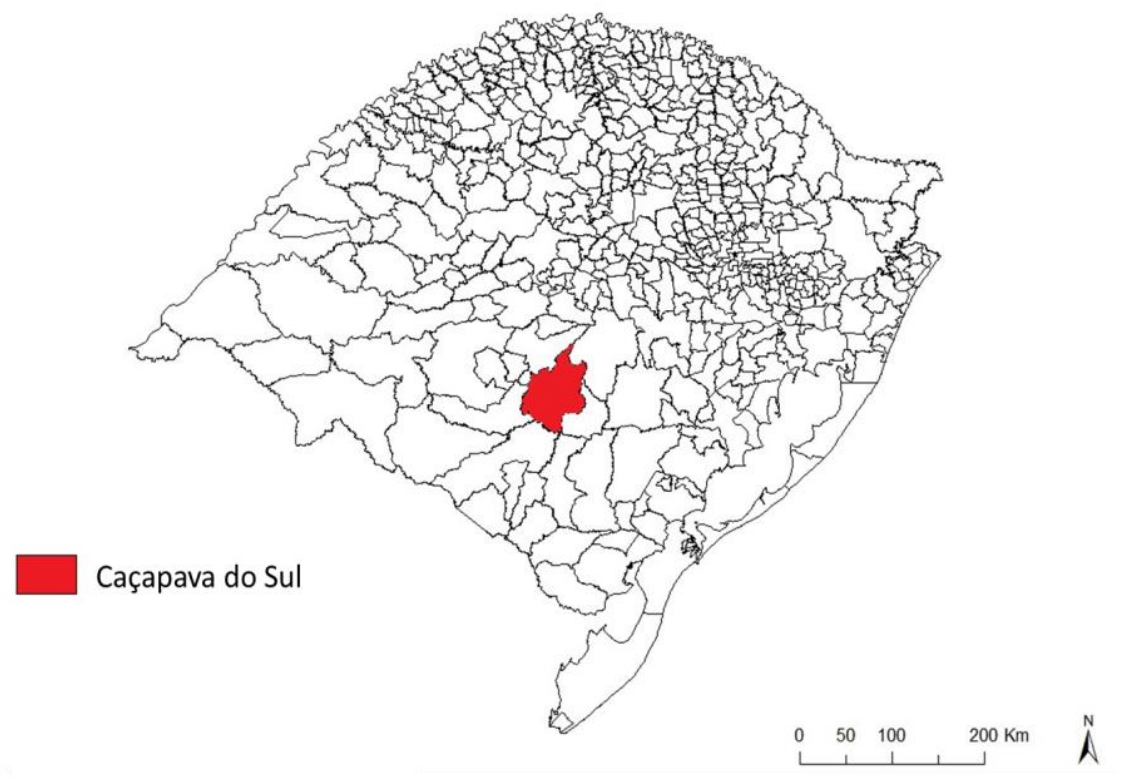

Fonte: Elaborado pelos autores.

No que se refere à história de ocupação do município, segundo Abrão (1979, p. 12), após um longo período de batalhas, os soldados de Castela acabaram perdendo território, revertido pelo domínio luso-brasileiro. Estima-se que em 1777 surgiu a "Paragem de Cassapava". Após os Dragões de Rio Pardo continuar a explorar esta região, descobriram um aldeamento de índios charruas, existente na clareira da mata virgem, representando um ponto estratégico para o descanso e restabelecimento das tropas em luta contra Castela. Com a ocupação da clareira, teve início a história que conhecemos de Caçapava do Sul, que surgiu de um acampamento militar com a finalidade de defender as fronteiras meridionais do Brasil. 
De acordo com registros históricos do município, Caçapava foi elevada à categoria de vila em 25 de outubro de 1831, sendo desmembrada do território do município de Cachoeira do Sul. No ano de 1911, a divisão administrativa do município estava constituída por seis (6) distritos: Caçapava, Durasnal, Seival, Minas, Lagoão e Santana da Boa Vista. De acordo com tais informações, a formação distrital do município foi sofrendo alterações, sendo que alguns distritos foram extintos, e no caso do distrito de Santana da Boa Vista foi elevada à categoria de cidade. Na atualidade, a divisão territorial é constituída de seis distritos: Caçapava do Sul, Bom Jardim, Carajá - Seival, Cerro do Martim, Forninho e Santa Bárbara.

A economia do município de Caçapava do Sul é formada por quatro pilares: a pecuária, a agricultura, o comércio local e a mineração, sendo a mineração responsável por $80 \%$ da produção de calcário produzida no RS. O município também é conhecido pelo seu potencial turístico, sendo a capital gaúcha do montanhismo e geodiversidade. As guaritas são consideradas a sétima maravilha gaúcha, conhecida pelos seus vales e rochas enormes, sendo palco de filmes e séries nacionais, também sendo destaque em outras belezas naturais como a pedra do segredo e a cascata do salso. Nos últimos anos, o município vem se projetando no cenário nacional, se destacando no plantio de oliveira, sendo um dos municípios com maior área plantada no sul do Brasil (PREFEITURA MUNICIPAL DE CAÇAPAVA DO SUL, 2017).

No que diz respeito à pecuária familiar, a partir de um trabalho de caracterização desenvolvido pela Empresa de Assistência técnica e Extensão rural (EMATER) de Caçapava do Sul, pode-se verificar a distribuição de categorias sociais existentes no rural do município (Tabela 01). Segundo o órgão de extensão rural, havia 1.500 famílias identificadas por pecuaristas familiares no ano de 2011.

Tabela 1: Divisão familiar por categoria social rural do município de Caçapava do Sul

\begin{tabular}{l|c}
\hline Categoria & No de Famílias \\
\hline Assentados crédito fundiário & 56 \\
\hline Quilombolas & 115 \\
\hline Indígenas & 60 \\
\hline Pecuarista familiar & 1500 \\
\hline Agricultor familiar & 900 \\
\hline Pecuarista não familiar & 700 \\
\hline Agricultor não familiar & 150 \\
\hline Total & $\mathbf{3 . 4 8 1}$ \\
\hline
\end{tabular}

Fonte: Emater (2011)

O número expressivo de famílias que a EMATER caracteriza como pecuarista familiar é regulamentada pelo decreto estadual $n=48.316$, de 31 de agosto de 2011 (RIO GRANDE DO SUL, 2011). A apresentação do município permite reforçar o predomínio da atividade pecuária historicamente e na contemporaneidade, justificando a escolha de estudo por essa categoria social produtiva em detrimento das demais formas familiares de produção. 


\section{MÉTODO DA PESQUISA}

A escolha do município de Caçapava do Sul para o local de realização deste estudo pode ser justificada pela presença da pecuária familiar, além da facilidade de acesso dos autores para a coleta de dados e realização das entrevistas. A pesquisa foi caracterizada como qualitativa, pelo foco na obtenção de dados por meio de entrevistas abertas e depoimentos. Para Hernández Sampieri et al. (2013), trata-se de ferramenta que permite coletar informações de uma família ou grupo de pessoas que viveu ou compartilhou fatos e experiências, narrando cronologicamente aspectos mais específicos. A principal unidade de análise correspondeu aos pecuaristas familiares, de modo que foram realizadas 16 entrevistas. Também, foram realizadas entrevistas com órgãos públicos e entidades representantes.

Para a coleta de dados, foram utilizados três roteiros diferentes. O primeiro foi caracterizado por questões abertas e fechadas, sendo aplicado aos pecuaristas familiares do município, cujas propriedades rurais estavam localizadas em diferentes distritos. Tendo em vista o objetivo da pesquisa, foram selecionados pecuaristas que pudessem descrever a história e suas relações com a atividade. $O$ segundo roteiro foi caracterizado por questões abertas e aplicado aos historiadores do município, denominados "informantes-chaves" sobre o histórico da região, com o foco sobre a atividade pecuária. O terceiro roteiro foi aplicado aos representantes de entidades e organizações sociais vinculados à pecuária familiar. Tais entrevistas foram pertinentes para obter informações sobre as características históricas, produtivas, sociais e econômicas que descrevem a pecuária familiar do município.

Para a seleção dos pecuaristas familiares que participariam da pesquisa, foram contatados a EMATER e o Instituto Padre Josimo, que indicaram os agricultores que poderiam fornecer as informações sobre a história e evolução da atividade na região. Não foi estabelecido um número de entrevistas a priori, sendo que a técnica "ponto de saturação" foi utilizada como sinalizadora para o encerramento desta etapa da pesquisa com os pecuaristas. Assim, o ponto de saturação é atingido quando as informações ficam repetitivas, não sendo necessário ampliar a coleta com outros informantes. Nesse sentido, a pesquisa incluiu oito localidades, a saber: Rincão da Salete, Rincão de Lourdes, Coxilha de São José, Carajá, Santa Barbinha, Varzinha, Irapuá e Picada da Graças.

Na segunda etapa da pesquisa, quanto aos informantes-chaves, foram entrevistados cinco historiadores e quatro atores locais ligados aos órgãos públicos e entidades representativas da pecuária no município, sendo eles extensionistas do escritório municipal da EMATER e do Instituto Cultural Padre Josimo, representante do Sindicato dos Trabalhadores Rurais e representante da Secretária de Agropecuária Indústria e Comércio. Tais informantes foram escolhidos pelos seus conhecimentos sobre a história e mudanças do município referente à atividade pecuária.

Quanto às técnicas de análise dos dados, primeiramente foi elaborada uma tipologia, tendo em vista identificar o perfil dos pecuaristas familiares locais. Para tanto, foram utilizados os dados correspondentes à atividade, considerando elementos da história e mudanças. A técnica "análise de conteúdo" viabilizou a identificação dos tipos de pecuaristas, que permitiu organizar os depoimentos com base no conteúdo das frases das famílias e dos informantes-chaves 
(HERNÁNDEZ SAMPIERI et al., 2013). As entrevistas foram gravadas e posteriormente transcritas. Os roteiros foram organizados seguindo três diferentes pontos: a trajetória e história da pecuária familiar, a interpretação sobre a região e os perfis dos pecuaristas. Essa divisão foi caracterizada como um guia para os diferentes roteiros utilizados, tendo em vista reunir as informações comuns para descrever a história e a trajetória da pecuária familiar no município. Quanto às questões específicas para os pecuaristas, o roteiro também abordou itens de identificação da família e suas atividades, tais como rebanhos, renda e mão-de-obra. No caso dos informantes-chaves, as questões específicas consideraram a interpretação deles sobre os diferentes tipos de pecuaristas no município.

O Quadro 1, a seguir, sintetiza as etapas da pesquisa e as técnicas utilizadas para a coleta e análise dos dados, conforme já descritas.

Quadro 1: Etapas da pesquisa e técnicas de coleta e análise dos dados

\begin{tabular}{|c|c|c|c|}
\hline \multicolumn{4}{|c|}{ Passo a passo da metodologia } \\
\hline Etapas & Com quem? & Qual objetivo? & Técnicas \\
\hline $1^{\circ}$ & Com 16 pecuaristas familiares & $\begin{array}{l}\text { Descrever o perfil e a história na } \\
\text { atividade pecuária }\end{array}$ & $\begin{array}{c}\text { Roteiro } \\
\text { Depoimentos } \\
\text { Gravações }\end{array}$ \\
\hline $2^{\circ}$ & 5 historiadores & $\begin{array}{l}\text { Identificar a história e mudanças } \\
\text { da pecuária local }\end{array}$ & $\begin{array}{c}\text { Roteiro } \\
\text { Depoimentos } \\
\text { Gravações }\end{array}$ \\
\hline $3^{\circ}$ & $\begin{array}{l}\text { EMATER, Secretaria de } \\
\text { Agropecuária Indústria e } \\
\text { Comércio e Sindicato dos } \\
\text { Trabalhadores Rurais }\end{array}$ & $\begin{array}{c}\text { Descrever a história e a } \\
\text { interpretação dos órgãos locais } \\
\text { sobre o perfil dos pecuaristas } \\
\text { familiares }\end{array}$ & $\begin{array}{c}\text { Roteiro } \\
\text { Depoimentos } \\
\text { Gravações }\end{array}$ \\
\hline \multirow{2}{*}{$\begin{array}{l}\text { Análise dos } \\
\text { dados }\end{array}$} & \multicolumn{3}{|c|}{ Técnicas utilizadas } \\
\hline & \multicolumn{3}{|c|}{$\begin{array}{l}\text { Organização dos dados - cruzamento e agrupamento das respostas de perfil e história da } \\
\text { pecuária - análise de conteúdo - elaboração de tipologia }\end{array}$} \\
\hline
\end{tabular}

Fonte: Elaborado pelos autores.

\section{ASPECTOS HISTÓRICOS, SOCIAIS E PRODUTIVOS DA PECUÁRIA FAMILIAR EM CAÇAPAVA DO SUL}

As transformações sociais, responsáveis pela formação desta categoria social no município de Caçapava do Sul, serão descritas ao longo dessa sessão. Para tanto, o texto está dividido em três partes, as quais serão possíveis obter uma síntese da formação histórica até os dias atuais. 
4.1 Aspectos sociais e produtivos na formação da pecuária familiar em Caçapava do Sul

A região sul do Rio Grande do Sul era considerada uma fronteira aberta, marcada por período na história de intensos combates entre Espanha e Portugal em disputas de demarcação de território, sobretudo no século XVI. A Coroa portuguesa tentando barrar as constantes invasões espanholas e a apropriação do gado bovino naqueles campos, fez surgir as primeiras concessões de terras, promovendo um processo de ocupação demográfica (ABRÃO, 1979).

Segundo Abrão (1979, p. 13), no ano de 1733 ocorreu a distribuição de terras nas chamadas "cartas de sesmarias", estabelecendo a ocupação dos primeiros povoamentos no Rio Grande do Sul. As primeiras demarcações de terras concedidas à exploração da área pelo homem se deram em troca da retribuição da prestação de serviços militares. Com a fixação do homem ao campo a partir das áreas disponibilizadas, estes primeiros colonizadores desta região construíram uma atividade econômica alicerçada na criação de bovinos, tendo um sistema extensivo em combinação com a farta disponibilidade de pastagens naturais do bioma Pampa.

No ano de 1780, foi concedida a primeira concessão de sesmaria no município de Caçapava do Sul (ABRÃO, 1979). Dessa forma, Ribeiro e Baldasso (1998) descrevem a economia baseada na criação bovina combinada com algumas produções diversas para subsistência, tendo a utilização de mão de obra escrava e a chegada de portugueses no ano de 1850.

Entre o ano de 1945 e 1965, há mudanças nos sistemas de produção do município, com o cultivo do trigo e a aquisição de novos instrumentos agrícolas. O período entre o ano 1965 a 1990 é marcado pela introdução de novas culturas no município, como o cultivo do feijão, tornando-se referência em produção, fixando-se devido à decadência da produção do trigo. Dois fatos marcaram este período: a intensificação do êxodo rural e o fracionamento das grandes propriedades, resultando na formação de significativo número de estabelecimentos rurais com áreas menores.

Entre 1990 a 1998, pode-se observar a expansão no cultivo da soja e a minimização do cultivo de outras culturas. A criação de bovinos e ovinos se intensifica em áreas menores devido às transformações ocorridas no campo, reflexo do fracionamento das propriedades gerando uma aglutinação de áreas menores no município.

Os aspectos descritos anteriormente foram determinantes para formação da atual realidade do município de Caçapava do Sul lembrando que a criação pecuária está enraizada culturalmente nas questões históricas e socioeconômicas que envolvem o processo de formação desta região até os dias atuais. As propriedades com áreas dedicadas à criação pecuária foram sofrendo redução nas dimensões de áreas e aumentando em quantidade numérica. No entanto, a atividade pecuária permanece como a principal atividade produtiva no município.

\subsection{A diversidade existente entre pecuaristas familiares em Caçapava do Sul}


A realização da pesquisa de campo possibilitou um melhor entendimento sobre a diversidade atual da pecuária familiar, em que o território do município de Caçapava do Sul apresenta proporções bastante extensas, formando a cada localidade diferentes tipos de produtores em relação ao meio no qual estão inseridos, influenciados por aspectos geográficos, culturais e socioeconômicos.

Após o cruzamento das respostas dos diferentes informantes-chaves e da análise sobre os depoimentos das famílias, pode-se afirmar que há dois tipos de pecuaristas familiares: o pecuarista familiar tradicional e o pecuarista familiar de transição. O Pecuarista Familiar Tradicional se apresenta como um produtor rural que desenvolve a criação pecuária desde os primórdios da ocupação desta região, e o Pecuarista Familiar de Transição é aquele que a partir das transformações que aconteceram no cenário rural nas últimas décadas, migrou de uma atividade agrícola para a criação pecuária como uma forma de adaptação às mudanças em curso.

De maneira mais específica, o Pecuarista Familiar Tradicional compreende o produtor rural herdeiro da divisão de terras originada nas sesmarias, ocupado pelos primeiros povoadores desta região. O fracionamento de campo contribuiu para a mudança da paisagem e da imagem construída sobre a criação pecuária tipicamente conhecida por ocupar extensas áreas de campo, mas que passa a gerar um produtor rural estabelecido em menores áreas, que continua a exercer a atividade de criação pecuária. A criação pecuária consiste de uma vocação repassada por meio das gerações. É possível relacionar o pecuarista familiar tradicional nos aspectos mais enraizados culturalmente na ligação "homem-cavalo" que forjou a imagem do gaúcho sobre o Pampa, sendo que algumas das localidades percorridas apresentam de forma mais explícita estes traços descritos anteriormente. Nas localidades de Varzinha, Santa Barbinha, Picada das Graças, Irapuá e Carajá são mais visíveis este tipo de produtor rural.

Por outro lado, o Pecuarista Familiar de Transição compreende aquele produtor rural formado pelas transformações produtivas ocorridas no meio rural, sendo consequência de uma série de fatores que levaram a um processo de transição da produção agrícola para a criação pecuária. Propriedades rurais com áreas relativamente menores em que desenvolviam atividade agrícola basicamente com a força animal e a utilização da mão de obra familiar passam a realizar a criação pecuária, uma vez que não conseguiram acompanhar os modelos produtivos impostos principalmente na década de 1960. Em consequência, esse modelo produtivo adotado por algumas famílias implicou no endividamento em virtude do custo para a aquisição de insumos e implementos para essa forma de produção. Portanto, o pecuarista familiar de transição foi forjado por um conjunto de fatores, desde a descapitalização da propriedade para aderir aos pacotes tecnológicos à grandes safras, que comprometeram a comercialização da produção. Somado a esses fatores, surge um produtor rural voltado para a criação pecuária pela necessidade de renda em uma atividade de custos baixos comparados à agricultura moderna. Pelo alto valor investido em insumos, a criação pecuária possibilitou uma forma mais segura de garantir a continuidade da família no meio rural. A presença desse produtor rural se apresentou de forma mais visível nas localidades de Rincão da Salete, Coxilha de São José e Rincão de Lourdes. As características que definem estes dois tipos de pecuaristas familiares estão sintetizadas no quadro a seguir. 
Quadro 2 - Diferenciações dos tipos de pecuarista familiares nas localidades em que ocorreram as entrevistas no município de Caçapava do Sul.

\begin{tabular}{|c|c|c|}
\hline $\begin{array}{c}\text { Características das } \\
\text { famílias de Pecuaristas } \\
\text { Familiares }\end{array}$ & Pecuarista Familiar Tradicional & Pecuarista Familiar Transição \\
\hline Origem das famílias & $\begin{array}{l}\text { Produtores rurais que exercem } \\
\text { atividade voltada à criação pecuária } \\
\text { desde os primeiros ocupantes desta } \\
\text { região a partir das Concessões de terras } \\
\text { "militares - portugueses". }\end{array}$ & $\begin{array}{l}\text { Produtores rurais resultantes de vários } \\
\text { fatores, entre eles: a descapitalização e a } \\
\text { dificuldade de aderir aos pacotes } \\
\text { tecnológicos e mecanização da "agricultura } \\
\text { moderna" e o endividamento em algumas } \\
\text { localidades após fartas colheitas, resultando } \\
\text { em um processo de emergência para a } \\
\text { criação pecuária, por ser uma atividade que } \\
\text { necessita de menor capital humano e } \\
\text { financeiro }\end{array}$ \\
\hline $\begin{array}{c}\text { Tamanho dos } \\
\text { estabelecimentos }\end{array}$ & Tamanho varia 20 a 123 hectares & Tamanho varia entre 12 a 54 hectares \\
\hline $\begin{array}{c}\text { Aspectos do rebanho } \\
\text { produtivo }\end{array}$ & $\begin{array}{l}\text { Produtores que desenvolvem cria e } \\
\text { recria em algumas localidades. É } \\
\text { possível verificar um melhoramento } \\
\text { genético significativo em bovinos e } \\
\text { ovinos, sendo comercializado através } \\
\text { de feiras, principalmente das } \\
\text { tradicionais feiras de outono e } \\
\text { primavera. Assistência técnica por parte } \\
\text { de órgãos de extensão rural e entidades } \\
\text { representantes. }\end{array}$ & $\begin{array}{l}\text { Produtores que desenvolvem a cria e recria, } \\
\text { a comercialização dos animais é feita por } \\
\text { meio direto, ou seja, sem terceiros para } \\
\text { efetuar a venda. } \\
\text { Limitações quanto à assistência técnica por } \\
\text { parte de órgãos de extensão rural e } \\
\text { entidades representantes. }\end{array}$ \\
\hline $\begin{array}{c}\text { Atividades } \\
\text { complementares }\end{array}$ & $\begin{array}{l}\text { Produtores que utilizam além da } \\
\text { criação pecuária, o arrendamento de } \\
\text { áreas para soja e eucalipto. Sendo } \\
\text { evidenciada em algumas localidades } \\
\text { uma diversificação incluindo como } \\
\text { fonte geradora de renda a apicultura e } \\
\text { a atividade agrícola para subsistência, } \\
\text { tendo em parte dos entrevistados o } \\
\text { benefício previdenciário }\end{array}$ & $\begin{array}{l}\text { Produtores que tem na atividade de criação o } \\
\text { bem de maior valor. Em algumas localidades } \\
\text { há o arrendamento para soja como forma de } \\
\text { incremento de renda, atividade agrícola } \\
\text { desenvolvida e comercializada na feira da } \\
\text { agricultura familiar, benefício previdenciário } \\
\text { e também existindo produtores que buscam } \\
\text { na venda de mão de obra para indústria e } \\
\text { comércio como forma para buscar a } \\
\text { complementação de renda }\end{array}$ \\
\hline $\begin{array}{l}\text { Acesso a políticas } \\
\text { públicas }\end{array}$ & $\begin{array}{c}\text { Produtores que tem acesso ao } \\
\text { Programa Estadual de Desenvolvimento } \\
\text { da Pecuária de Corte Familiar - PECFAM } \\
\text { e as linhas de crédito do PRONAF }\end{array}$ & $\begin{array}{l}\text { Produtores que tem acesso às linhas de } \\
\text { crédito do PRONAF. Porém, em algumas } \\
\text { localidades há falta de informações quanto } \\
\text { às políticas públicas. }\end{array}$ \\
\hline
\end{tabular}

Fonte: Elaborado pelos autores com base em pesquisa de campo.

A sistematização apresentada permite mostrar as diferenças nos dois tipos de pecuaristas presentes no município de Caçapava do Sul. Assim, o próximo tópico consiste em apresentar como tais trajetórias podem ter relação com o modo de produção atual. 


\subsection{Características atuais dos pecuaristas familiares de Caçapava do Sul}

A trajetória da atividade pelos tipos de pecuaristas familiares foi por meio de conhecimentos oriundos de gerações familiares, ou por mudanças nos sistemas produtivos na agricultura que resultaram em um produtor rural que migrou da atividade agrícola para a criação pecuária. Nos dois tipos de pecuaristas familiares, a comercialização do produto oriundo da criação pecuária significa "o seu bem de maior valor comercial", sendo este a maior fonte de sustentação econômica da família no meio rural.

Nos relatos das entrevistas é possível descrever que os pecuaristas familiares tradicionais têm dentro dos limites da propriedade, além da criação pecuária, o cultivo agrícola de hortas para a subsistência familiar, sendo visualizados em todos os produtores entrevistados. Dentro desse conjunto, existem algumas exceções em que as propriedades contam com uma maior diversificação, desenvolvendo a avicultura, apicultura, além do arredamento para o cultivo de soja que complementam na fonte de renda familiar, sendo que entre os entrevistados pelo menos um dos residentes recebe benefício previdenciário, totalizando $75 \%$ dos entrevistados. A renovação na condução da propriedade rural é visualizada em número baixo, sendo apenas $25 \%$ das propriedades. O tamanho médio das propriedades dos pecuaristas familiares tradicionais entrevistados é de 69 hectares.

Os pecuaristas familiares de transição têm uma diversificação superior em relação ao tipo tradicional. Essa diferença pode ser compreendida pelo tamanho médio, apresentando menor dimensão territorial, em média 26,4 hectares. Esses produtores rurais destinam uma parcela da área para atividades agrícolas de subsistência e comercial, criação de vacas de leite, indústria caseira, apicultura, suinocultura e arrendamento para o cultivo da soja. Dessa forma, $62,5 \%$ dos entrevistados descrevem que pelo menos um dos integrantes da residência recebe benéfico previdenciário, sendo que a renovação na condução da propriedade é visualizada em $37,5 \%$ das propriedades.

Os pecuaristas familiares das localidades de Rincão da Salete e Rincão de Lourdes destacam problemas como a exaustão do solo prejudicando a qualidade das pastagens, influenciando diretamente no nível da qualidade do pasto destinado ao pastoreio dos animais. Tais proprietários, identificados como "pecuaristas familiares de transição", correspondem aos produtores rurais que exerciam atividades agrícolas, sendo que algumas dessas regiões foram consideradas grandes produtoras de trigo e feijão. Porém, nas últimas décadas, está ocorrendo uma transição da agricultura para a pecuária.

Segundo relatos, com o despovoamento das localidades, houve a alteração da paisagem no meio rural, formando um cenário de muitas taperas ${ }^{2}$ pelas localidades percorridas no interior do município de Caçapava do Sul, ficando mais evidente no $3^{\circ}$ Distrito denominado "Cerro do Martim", na localidade de Varzinha. Entre as principais dificuldades enfrentadas pelos pecuaristas familiares destacam-se a limitação de mão de obra e a falta de segurança no campo. Em todas as

${ }^{2}$ Tapera é uma palavra de origem indígena que tem em seu significado casa velha ou abandonada. 
localidades, os agricultores relataram a preocupação frente a escassez de jovens e abigeato. Tais situações evidenciam a incerteza quanto às perspectivas futuras na continuidade das atividades agropecuárias do município e região. No $3^{\circ}$ Distrito denominado Cerro do Martim na localidade de Rincão da Salete foi relatado um fato inverso, ocorrendo um deslocamento da área urbana para o meio rural, principalmente de pessoas que utilizam benefícios previdenciários, sendo que esta localidade foi uma das que se identificou este tipo de produtor rural, o pecuarista familiar de transição.

No $6^{\circ}$ Distrito denominado como Carajá - Seival na localidade de Carajá foi identificada uma propriedade rural do tipo pecuarista familiar tradicional. Nesta propriedade em específico, há a inserção vários projetos da EMATER, os quais estão fomentando o melhoramento de campo nativo e o melhoramento genético, sendo formas de dar visibilidade a pecuária familiar. Além disso, destaca-se o papel relevante da assistência técnica nas mudanças da atividade, com o investimento em tecnologia e ações inovadoras.

Porém, nas proximidades da localidade de Coxilha de São José foi identificado um fato diferente da localidade Carajá. A partir das entrevistas com produtores rurais do tipo pecuaristas familiares de transição, foi constatada a necessidade de uma maior visibilidade por parte dos órgãos públicos e entidades representantes para o enfrentamento das dificuldades. Os produtores rurais exercem atividades em áreas menores em relação aos entrevistados das demais localidades, tendo uma localização de proximidade com o meio urbano, influenciando num cenário futuro em que estas famílias possam vir a deixar as propriedades rurais se não houver alternativas para continuidade das atividades agropecuárias.

Situado no $5^{\circ}$ Distrito denominado de Santa Bárbara, na localidade de Santa Barbinha foram encontrados os pecuaristas familiares do tipo "pecuarista familiar tradicional". Estes produtores são beneficiados por meio de projetos em que se insere a criação pecuária, tendo uma associação que é considerada modelo para o município de Caçapava do Sul e região, contribuindo com o cooperativismo para a localidade, desempenhando um papel fundamental na vida dos pecuaristas familiares.

No $1^{\circ}$ Distrito denominado Caçapava do Sul na localidade de Rincão de Lourdes foi evidenciada a introdução do cultivo da soja por meio de arrendamento em uma propriedade rural em que se encontra o produtor rural tipo pecuarista familiar de transição. Da mesma forma, no $3^{\circ}$ Distrito denominado de Cerro do Martim na localidade de Irapuá é encontrado um produtor rural tipo pecuarista familiar tradicional, sendo também evidenciado o arrendamento de uma parcela de área dentro da propriedade rural para o cultivo da soja.

Tais produtores correspondem a dois tipos de pecuaristas familiares diferentes que recorreram ao arrendamento de uma parcela da área para o cultivo da soja pelo período de seis meses. Após este período, a área é entregue aos pecuaristas, que é utilizada para pastagem. Nesse sentido, há uma maior preocupação por parte do pecuarista sobre a seguridade da criação pecuária frente ao rigor do inverno que às vezes é acompanhada pela perda de animais. A preparação destas áreas pelos pecuaristas em muitos casos é inviável frente à disponibilidade de 
recurso financeiro e de material humano, sendo que ambos os tipos de pecuaristas familiares procuram formas para buscar novas fontes de renda e condições para a continuidade da atividade.

Na localidade de Picada das Graças, situada no $5^{\circ}$ Distrito denominado Bom Jardim foi identificada empresas exploradoras na área de mineração, em que emprega boa parte dos moradores da região de forma direta ou indireta. A localidade, sendo formada em grande parte por pequenas propriedades rurais, desenvolve uma atividade de criação pecuária de baixo retorno financeiro, em que grande parte dos produtores rurais acaba buscando fora da propriedade rural uma atividade complementar para garantir a sobrevivência familiar. Nesta localidade há a existência dos dois tipos de pecuaristas, o tipo tradicional e em transição.

Com relação às políticas públicas, os pecuaristas familiares utilizam linhas de crédito do PRONAF (Programa Nacional de Fortalecimento da Agricultura Familiar), sendo uma das práticas para fomentar a atividade de criação pecuária. Um dos fatos que justifica essa realidade refere-se ao tamanho das propriedades, que não ultrapassam 140 hectares.

\section{CONSIDERAÇÕES FINAIS}

A realização do estudo permitiu identificar, no espaço territorial do município de Caçapava do Sul, dois tipos de pecuaristas familiares: o Pecuarista Familiar Tradicional e o Pecuarista Familiar Transição. Constata-se que o tipo pecuarista familiar de transição apresenta maiores semelhanças com a agricultura familiar, uma vez que se trata de um tipo de produtor rural que migrou de uma atividade agrícola para a criação pecuária, inserido em menores áreas de terra se comparado ao tipo pecuarista familiar tradicional. O pecuarista familiar de transição utiliza diversos mecanismos para garantir a sua sobrevivência familiar, sejam elas atividades produtivas formais ou informais, desde indústrias caseiras à comercialização de produtos por meio das feiras da agricultura familiar. No entanto, o que o diferencia do agricultor familiar é a principal atividade produtiva - a criação pecuária, produto de maior retorno financeiro na propriedade.

Os dois tipos, apesar das diferenças de formação, e até mesmo nas características de comportamento na busca de renda para a sobrevivência e continuidade das atividades no meio rural têm semelhanças nas dificuldades enfrentadas atualmente. De maneira geral, a incerteza comumente sinalizada diz respeito ao esvaziamento do meio rural e, consequentemente, a descontinuidade das atividades agropecuárias por um membro da família. Estudos que busquem entender a trajetória histórica e as vulnerabilidades que acometem a pecuária familiar são necessários para evidenciar as diferentes realidades em que a atividade é desenvolvida.

\section{REFERÊNCIAS BIBLIOGRÁFICAS}

ABRÃO, N. S. (1979). História do município de Caçapava do Sul: lendas, folclore e turismo. Ed.2, p. 12-13-14-54-56. 
ANDREATTA, T. (2009). Bovinocultura de corte no Rio Grande do Sul: um estudo a partir do perfil dos pecuaristas e organização dos estabelecimentos agrícolas. Tese (Doutorado em Desenvolvimento Rural). Programa de Pós-Graduação em Desenvolvimento Rural, Universidade Federal do Rio Grande do Sul, Porto Alegre.

ANDREATTA, T.; WAQUIL, P.D.; MIGUEL, L.A. (2016). A organização dos estabelecimentos de pecuária de corte de base familiar no Rio Grande do Sul. In: WAQUIL, P. D. et al. (Org.). Pecuária familiar no Rio Grande do Sul: história diversidade social e dinâmicas de desenvolvimento. Porto Alegre: editora da UFGRS. p. 65.

BALDASSO, N. A.; RIBEIRO, C. M. (Coord.). (1998). Diagnóstico dos sistemas agrários de Caçapava do Sul. Porto Alegre: EMATER/RS, p. 92.

BORBA, Marcos F. S. (2016). Desenvolvimento territorial endógeno: o caso do Alto Camaquã. In: WAQUIL, P. D. et al. (Org.). Pecuária familiar no Rio Grande do Sul: história, diversidade social e dinâmicas de desenvolvimento. Porto Alegre: Editora da UFRGS. p. 187-214.

CARVALHO, Paulo C.F. et al. (2006). Produção Animal no Bioma Campos Sulinos. Brazilian Journal of Animal Science, João Pessoa, v. 35, n. Supl. Esp., p. 156-202.

CESAR, G. (2005). Origem da economia gaúcha (o boi e o poder). Porto Alegre: CORAG.

COTRIM, M.S. (2003). "Pecuária familiar" na região da Serra do Sudeste do Rio Grande do Sul: um estudo sobre a origem a situação socioagroeconômica do pecuarista familiar no município de Canguçu RS. 2003. Dissertação (Mestrado em Desenvolvimento Rural). Programa de Pós-Graduação em Desenvolvimento Rural, Universidade Federal do Rio Grande do Sul, Porto Alegre.

EMATER. (2011). Escritório Municipal de Caçapava do Sul. Caracterização das categorias sociais existentes no meio rural do município de Caçapava do Sul.

HERNÁNDEZ SAMPIERI, R. et al. (2013). Metodologia de pesquisa. Porto Alegre: Penso.

IBGE. (2009). Censo Agropecuário 2006. Rio de Janeiro: IBGE.

IBGE. (2019). Censo Agropecuário 2017. Rio de Janeiro: IBGE.

INSTITUTO BRASILEIRO DE GEOGRAFIA E ESTATÍSTICA. Histórico do município. Disponível em < http://cidades.ibge.gov.br/painel/historico.php?lang=\&codmun=430280\&search=rio-grandedo-sul|cacapava-do-sul|infograficos:-historico> Acesso em 14 de abril, 2017.

INSTITUTO BRASILEIRO DE GEOGRAFIA E ESTATísTICA. (2017). Sistema IBGE de Recuperação Automática - SIDRA. Variável - população residente - unidade territorial Caçapava do Sul (RS). Disponível em <https://sidra.ibge.gov.br/Tabela/200\#resultado> Acesso em 20 de abril.

MATTE, A. SPANEVELLO, R. M. ANDREATTA, T. (2015). Perspectivas de sucessão em propriedades de pecuária familiar no município de Dom Pedrito - RS. Holos, Natal/RN, n. 31, v. 1. 
MATTE, A. SPANEVELLO, R.M. ANDREATTA, T. (2016). Reprodução social na pecuária familiar. In: WAQUIL, P. D. et al. Pecuária familiar no Rio Grande do Sul: história, diversidade social e dinâmicas de desenvolvimento. Porto Alegre: Editora da UFRGS.

MATTE, A. (2019). Mudanças produtivas no Pampa brasileiro: impactos, vulnerabilidade e estratégias de reação. In: SUZUKI, Júlio César; LAURENT, François; ARAÚJO, Valterlei Borges. (Org.). Transições produtivas, agroecológicas e culturais no campo brasileiro. 1ed.São Paulo: FFLCH/USP, v. 1, p. 93-123.

MOREIRA, J. G.; CONTERATO, M. A.; MATTE, A. (2019). Transformações produtivas no Pampa brasileiro: influências do avanço da soja na bovinocultura de corte. Campo.Território, v. 14, p. 179-207.

NABINGER, C. (2006). Manejo e produtividade das pastagens nativas do subtrópico brasileiro. In: Dall'Agnol, M.; Nabinger, C.; Rosa, L.M.; et al. (org.) Simpósio de forrageiras e pastagens, 1, 2006, Porto Alegre, Anais... Canoas: Ulbra. p. 25-76.

PREFEITURA MUNICIPAL DE CAÇAPAVA DO SUL. História. Disponível em < http://www.cacapava.rs.gov.br/> Acesso em 10 de agosto de 2017.

RIBEIRO, C. M. (2009). Estudo do modo de vida dos pecuaristas familiares da região da campanha do Rio Grande do Sul. Tese (Doutorado em Desenvolvimento Rural). Programa de Pós-Graduação em Desenvolvimento Rural, Universidade Federal do Rio Grande do Sul, Porto Alegre.

RIBEIRO, C.M. (2016). O modo de vida dos pecuaristas familiares no Pampa brasileiro. In: WAQUIL, P. D. et al. (Org.). Pecuária familiar no Rio Grande do Sul: história diversidade social e dinâmicas de desenvolvimento. Porto Alegre: editora da UFGRS. p. 102.

RIBEIRO, C.M. (2003). Pecuária familiar na região da campanha do Rio Grande do Sul. Pecuária familiar. EMATER Rio Grande do Sul - ASCAR, serie realidade rural, v. 34. Porto Alegre. p. 42.

RIO GRANDE DO SUL. Decreto no 48.316, de 31 de agosto de 2011. Regulamenta o Programa Estadual de Desenvolvimento da Pecuária de Corte Familiar - PECFAM, instituído pela Lei no 13. 515 , de 13 de setembro de 2010. Disponível em <http://www.al.rs.gov.br/filerepository/repLegis/arquivos/DEC\%2048.316.pdf > Acesso em 08 de março, 2017.

WAQUIL, P. et al. (2016). Pecuária familiar no Rio Grande do Sul: a ressignificação de uma categoria social. In: Pecuária familiar no Rio Grande do Sul: história, diversidade social e dinâmicas de desenvolvimento. Porto Alegre: Editora da UFRGS.

\section{COMO CITAR ESTE ARTIGO:}

Freitas, T. R. de, Agne, C. L., Matte, A. (2020). Pecuária familiar no município de Caçapava do Sul/RS: aspectos históricos, sociais e produtivos Holos. 36(6), 1-18. 


\section{THIAGO RODRIGUES DE FREITAS}

ecnólogo em Gestão Ambiental com Especialização em Gestão em Desenvolvimento Rural. Atualmente cursando Bacharelado em Agronomia - UERGS. E-mail: thiago-freitas@uergs.edu.br

ORCID ID: https://orcid.org/0000-0002-1283-8746

\section{CHAIANE LEAL AGNE}

Bacharel em Administração, Mestre e Doutora em Desenvolvimento Rural - UFRGS. Professora Adjunta em Desenvolvimento Rural na UERGS. Unidade Cachoeira do Sul -Campus Regional V. E-mail: chaianeagne@uergs.edu.br

ORCID ID: https://orcid.org/0000-0002-8779-045X

\section{ALESSANDRA MATTE}

Zootecnista, Mestre e Doutora em Desenvolvimento Rural (PGDR/UFRGS). Professora adjunta na UTFPR. Santa Helena. PR. E-mail: alessandramatte@yahoo.com.br ORCID ID: https://orcid.org/0000-0002-0502-6643

Editor(a) Responsável: Francinaide de Lima Silva Nascimento Pareceristas Ad Hoc: SABINO DA SILVA NETO E GENILDO PEREIRA

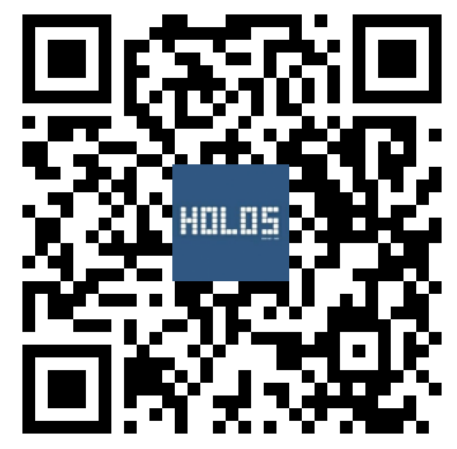

